\title{
Assessment of newborns at birth for cardio- respiratory status requiring resuscitation and outcomes in a community hospital
}

\section{Introduction}

Apgar score (AS) at birth is used to assess the clinical condition of the baby at birth. Since its inception by Dr. Virginia Apgar in 1953, the score has been used universally to assess the newborns and identify depressed newborns who require intensive cardiopulmonary resuscitation. ${ }^{1}$ One of the serious outcomes of very low AS at 5 and 10 minutes at birth is the occurrence of neonatal encephalopathy in infants of 36 weeks of more presumably caused by hypoxic ischemic encephalopathy (HIE). Our main aim of the study is to concentrate to identify infants who meet the criteria for HIE for early identification and referral to the center for management, however low Apgar score is also common amongst premature infants, congenital Perinatal and neonatal infection, congenital malformation, neonatal surgical condition and infants delivered by Maternal Fetal emergency condition. Despite the advances made in the field of Perinatal and neonatal medicine, the rate of hypoxic ischemia continues to be at a constant with an incidence of 2-3 per 1000 live births in USA. HIE is a major cause of morbidity and mortality in term newborns infants. ${ }^{2}$ HIE has long term outcomes including cerebral palsy. Novel approaches like selective head and whole body cooling have become a standard of care to protect the brain from reperfusion injury, thereby improving their clinical outcome. ${ }^{3}$

\section{Methods}

Our institution is located in an urban area serving a predominantly minority and immigrant population of low socio-economic status. The hospital has data of a median income of $\$ 13,776 /$ year with a population consisting of a majority of Hispanic patients and a minority of African American patients. Many women do not seek prenatal care early enough to care for themselves and for their fetus during pregnancy with documented multiple medico social issues affecting the mother, the fetus and the newborn at birth. We conducted a retrospective descriptive study during a period of 7 years between 2006-2012 to identify severely depressed live newborns (by assessing cardio-respiratory status at birth) with $\mathrm{AS} \leq 3$ at 1 minute. The data was collected by $\log$ book maintained in the NICU which was monitored by the senior author on a daily basis, electronic medical data, individual case presentation and discussion of the cases in morbidity and mortality obstetrics pediatrics conference and reviewed by Pediatric QI for Quality Care issues. The outcomes of theses newborns were assessed to identify proportions of the various kinds of respiratory support needed, medications used, $\mathrm{pH}$ and base excess values of cord blood gas and treatment. Also, the proportion that survived post intervention and those with HIE were assessed.

\section{Results}

Over the study period of 7 years, there were 16725 live births. Out of those, 210 with had $\mathrm{AS} \leq 3$ at 1 minute, with an incidence of 12.5/1000.After resuscitation, 43 infants had an $\mathrm{AS} \leq 3$ at 5 minutes

\author{
Volume 8 Issue 5 - 2018
}

\begin{abstract}
Sunanda Kandi, Tarik Zahouani, Olga Brea, Wallis Tavarez, Upma Suneja, Benamanahalli Rajegowda

Department of Pediatrics, Lincoln Medical and Mental Health Center, Affiliated with Weill Cornell Medical College, USA
\end{abstract}

\author{
Correspondence: Tarik Zahouani, Department of Pediatrics, \\ Lincoln Medical and Mental Health Center, Affiliated with Weill \\ Cornell Medical College, Bronx, NY, USA \\ Email tarikzahouani@gmail.com
}

Received: July 27, 2018 | Published: September 24, 2018

with an incidence of 2.5/1000. And remaining 14 had $\mathrm{AS} \leq 3$ at10 minutes with an incidence of $0.83 / 1000$, of these 14 , three full term babies had severe congenital anomalies. The mean Apgar scores were 2.0, 5.4 and 6.4 at first, fifth and tenth minutes respectively. The mean cord $\mathrm{pH}$ was 7.18 and it ranged between 6.52 and 7.63 . The gestational age ranged between 22 and 43 weeks and the mean gestational age was 32.5 weeks \pm 6.11 weeks. The birth weight was between 480 and $4805 \mathrm{~g}$ and the mean weight was $2072.9 \mathrm{~g} \pm 1214.99 \mathrm{~g}$. The average length of stay in the NICU was 29.7 days and it ranged between 0 and 142 days.67 infants were delivered via normal spontaneous vaginal delivery (NSVD) (31.9\%) and 143 via cesarean section (C-section) $(68.09 \%)$. The demographic characteristics are summarized in Table 1. 97 infants required intubation and 3 were diagnosed with HIE and were transferred to a tertiary care center to receive hypothermia therapy and they subsequently survived with fairly good outcome, they are discussed in Table 2. 15 infants died and the causes of death are listed in Table 3 .

\section{Discussion}

Our hospital is a New York State designated level III neonatal tertiary care center with an active residency program that provides total care for all infants under close supervision by neonatal attending around the clock coverage since we do not have physician extenders. Almost all of our staff have been trained and certified in neonatal resuscitation program and the neonatal service have formed a neonatal response team composed of neonatal attending, pediatric resident and neonatal nurse to respond to all neonatal high risk deliveries. Apgar score gives an idea about compromise of the neonate which sometime not available via biochemical measurements. ${ }^{1}$ Every year up to 12,000 infants are at risk for hypoxic-ischemic encephalopathy in the United States. ${ }^{2}$ Therapy with hypothermia with head or whole body cooling has improved the outcome with a number needed to treat of 6-9 infants to prevent 1 case of death or significant neuro developmental disability. However, strict adherence to the eligibility criteria for hypothermia treatment, initiation and duration of the treatment is 
essential to achieve the best possible outcome. ${ }^{3}$ Most of our babies who had very low AS were less than 27 weeks of gestational age, and 12 out of 15 infantswho died were also less than 27 weeks of gestational age. Whereas three full term babies born with low AS had severe congenital anomalies and died. Whereas the remaining three full term babies treated for HIE survived. Based on our review, our institution have significantly improved the outcome of infants with very low AS, thereby decreasing the number of HIE cases by effectively preventing and managing low AS with early intervention. This was a combined effort of obstetricians, perinatologists and neonatal care providers.

Table I Demographic characteristics

\begin{tabular}{|c|c|c|c|}
\hline & & Min - Max & $\begin{array}{l}\text { Mean } \pm \text { Standard } \\
\text { deviation }\end{array}$ \\
\hline $\begin{array}{l}\text { Gestational age } \\
\text { (weeks) }\end{array}$ & & $22-43$ & $32.5 \pm 6.1$ \\
\hline Maternal age (years) & & $15-48$ & $27.5 \pm 6.9$ \\
\hline Birth weight (grams) & & $480-4805$ & $2072.9 \pm 1214.9$ \\
\hline Apgar score at I min & & $0-3$ & $2.0 \pm 0.92$ \\
\hline Apgar score at $5 \mathrm{~min}$ & & $0-9$ & $5.4 \pm 2.2$ \\
\hline Apgar score at $10 \mathrm{~min}$ & & $0-9$ & $6.4 \pm 2.1$ \\
\hline Cord $\mathrm{pH}$ & & $6.52-7.63$ & $7.18 \pm 0.18$ \\
\hline Cord Base excess & & $-28-4.9$ & $-7.92 \pm 5.95$ \\
\hline \multirow[t]{2}{*}{ Length of stay (days) } & & 87 & 5 \\
\hline & & Number & Percentage \% \\
\hline \multirow[t]{2}{*}{ Delivery type } & NSVD & 67 & 31.9 \\
\hline & C-section & 143 & 68.09 \\
\hline
\end{tabular}

Table 2 Hypoxic Ischemic Encephalopathy cases

\begin{tabular}{llll}
\hline & Case I & Case 2 & Case 3 \\
\hline Gestational age (weeks) & 36 & 36 & 37 \\
Maternal age (years) & 23 & 24 & 19 \\
Birth weight (grams) & 3550 & 2425 & 3400 \\
Apgar score at Imin & 0 & I & I \\
Apgar score at 5min & 0 & I & 8 \\
Apgar score at IOmin & 0 & I & 8 \\
Apgar score at I5min & I & 4 & N/A \\
Cord pH & 6.7 I & 6.82 & 6.78 \\
Cord Base excess & -24 & -20 & -2 I \\
Delivery type & C-section & C-section & C-section \\
Ventilator support & Intubation & Intubation & Intubation \\
Fetal tracing & Non Reassuring Fetal Heart Rate & Bradycardia & Category I tracing \\
Gestational diabetes & Yes & Yes & No \\
Maternal Hypertension & No & Yes & No \\
Twins & No & No & No \\
Preterm labor & Yes & No & No \\
Preterm premature rupture of membranes & No & No & Yes \\
Maternal Bleeding & No & Yes & Yes \\
Steroid use & No & No & No \\
Cord Prolapse & No & No & Yes \\
Length of stay (hours) & 3 & 3.5 & 4 \\
\hline
\end{tabular}


Table 3 Causes of death

\begin{tabular}{|c|c|c|}
\hline $\begin{array}{l}\text { Gestational } \\
\text { age }\end{array}$ & Cause of death & $\begin{array}{l}\text { Age at } \\
\text { death }\end{array}$ \\
\hline 27 weeks & Cardio respiratory arrest due to respiratory failure, hypoplastic lungs & 2 hours \\
\hline 39 weeks & $\begin{array}{l}\text { Multiple anomalies: bilateral coloboma , microphthalmia, cleft lip/palate, retrognathia, polydactyly (7 digits in } \\
\text { right hand, } 8 \text { in left hand) }\end{array}$ & 10 hours \\
\hline 23 weeks & Multiples organ failure & I day \\
\hline 24 weeks & Grade IV Intra ventricular hemorrhage, with periventricular leukomalacia and porencephalic cyst & 38 days \\
\hline 23 weeks & Extreme prematurity & $\begin{array}{l}\text { Few } \\
\text { minutes }\end{array}$ \\
\hline 25 weeks & Cardio respiratory arrest after placental abruption & $\begin{array}{l}\text { Few } \\
\text { minutes }\end{array}$ \\
\hline 38 weeks & Trisomy 18 & 18 days \\
\hline 22 weeks & Extreme prematurity & I hour \\
\hline 23 weeks & Extreme prematurity & 2 days \\
\hline 24 weeks & Grade IV Intra ventricular hemorrhage, pulmonary hemorrhage & 5 days \\
\hline 24 weeks & Sepsis & I5 days \\
\hline 22 weeks & Extreme prematurity & $\begin{array}{l}\text { Few } \\
\text { minutes }\end{array}$ \\
\hline 23 weeks & Extreme prematurity & $\begin{array}{l}\text { Few } \\
\text { minutes }\end{array}$ \\
\hline 39 weeks & Anencephaly & 9 hours \\
\hline 23 weeks & Extreme prematurity & 3 days \\
\hline
\end{tabular}

\section{Conclusion}

Low Apgar scores are known to be associated with poor prognosis in the newborns. Continued efforts to reduce the rate of low Apgar score is the cornerstone to prevent adverse outcome and neurologic impairment not only in low birth weight but also in full term babies. Prevention is a rule by working with obstetricians and timely identifying the problems and management of infants by neonatal team to help prevent some but may not be all. Our institution was able to decrease the incidence of low AS by 10 minutes by early recognition, communication and the team approach with the prompt availability of the neonatal response team.

\section{Acknowledgement}

The authors declare no potential conflicts of interest with respect to the research, authorship, and/or publication of this article.

\section{Conflict of Interest}

The authors declared there is no conflict of interest.

\section{References}

1. Thorngren Jerneck K, Herbst A. Low 5-minute Apgar score: a population-based register study of 1 million term births. Obstet Gynecol. 2001;98(1):65-70

2. Wachtel EV, Hendricks-Muñoz KD. Current management of the infant who presents with neonatal encephalopathy. Curr Probl Pediatr Adolesc Health Care. 2011;41(5):132-153.

3. Hoque N, Chakkarapani E, Liu X. A comparison of cooling methods used in therapeutic hypothermia for perinatal asphyxia. Pediatrics. 2010;126(1):e1240-130. 